\title{
Satellite will probe mutating seeds in space
}

\section{David Cyranoski, Tokyo}

Chinese plant scientists are hoping that a proposed new satellite will deliver not only agricultural breakthroughs but also a greater understanding of how to make plants mutate.

The satellite project, which was announced late last month, is designed to expose plant seeds to cosmic radiation, zero gravity and other effects that are encountered only in space.

It aims to "make breakthrough mutations with important economic significance, such as crop yield and quality", according to Liu Luxiang, director of the Space Breeding Centre at the Chinese Academy of Agricultural Sciences, which is promoting the project.

Chinese scientists say they have already discovered several rare, inheritable genetic mutations - capable, they say, of producing giant sweet peppers as well as improving the quality of rice and wheat - using recoverable satellites and high-altitude balloons.

The new project aims not only to identify more mutants, but also to establish their causes. "It could take advantage of the many kinds of radiation, such as gamma rays, $\mathrm{X}$ rays and secondary emissions, at many ener-

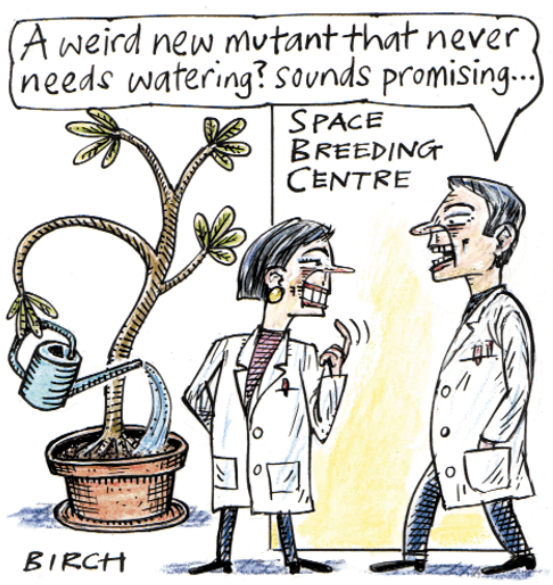

gylevels, that can affect plants and seeds," says Didier Schmitt of the European Space Research and Technology Centre (ESTEC), a European Space Agency laboratory in Noordwijk, the Netherlands, which is not involved in the project.

The satellite will be designed with minimum protection against radiation - in contrast to the heavily protected research facilities sent into space by Russia and the United States. Radiation detectors and special com- partments - such as one protected against radiation and another containing a gravity simulator - will help researchers to identify the role of these factors in causing mutations.

The fact that cosmic radiation causes mutations is well known, but the effect of microgravity remains disputed. Some researchers think that the combination of the two could produce some interesting results. "There might very well be a synergy effect of radiation and lack of gravity," says Enno Brinckmann, ESTEC's senior biologist.

Seeds will be loaded onto the satellite, which will then be launched into orbit. When the satellite is recovered, the seeds will be grown and screened for mutants in a process that will take three to five years.

The plan, which could cost as much as RMB200 million (US\$25 million) for the satellite alone, has yet to be approved by the Chinese government, but Liu says he is optimistic that it will go ahead.

The project "would be unique as an unattended facility specifically for plant mutation studies," says Brinckmann. Schmitt agrees that it would complement other satellite-based biological research as well as experiments planned for the International Space Station.

\section{Animal labs fearful over activists' plan to name names}

Quirin Schiermeier and Alison Abbott, Munich Biomedical research institutes in Germany are on the alert this week over plans by animal rights advocates to publish the names and work addresses of scientists who use laboratory animals.

The 400-page list will be published on 24 April as part of a campaign by the Bundesverband der Tierversuchsgegner (BVTVG), an organization that opposes any form of animal experimentation.

BVTVG produced its list by systematically analysing 1,800 scientific papers published in 1998 and 1999. "We will point the finger at this hidden side of research," says Corina Gericke, a spokeswoman for the group.

Today's animal rights movement in Germany is professionally organized, and financially strong. But there have been few violent incidents, and only occasional cases of harassment. Most protests have concerned animal transportation and the fur trade, rather than research.

Research groups fear this may be about to change. "There are clear signs that protests are switching to animal experimentation," says Ivar Aune, spokesman for the research lobby group Society for Health and Research.

Last month, for example, more than 1,000 participants at a physiologists' meeting in Berlin were evacuated after a bomb threat by an anonymous animal rights group.

Aune fears that militant activism could increase in the wake of this latest personalized campaign. He says research institutes should increase safety measures.

The University of Düsseldorf, which three years ago was stung by a disinformation

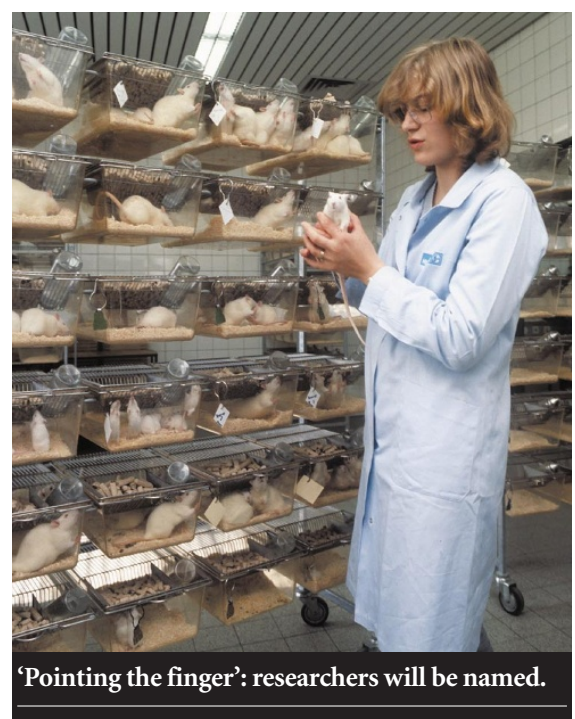

campaign by animal activists, is planning its own counter-attack. "It is important for the public to understand that all animal experiments are carried out in line with strict German animal protection laws, and only after all alternative methods have been explored and excluded," says Annemarie Treiber, president of Germany's Society for Laboratory Animal Science, and the official responsible for animal welfare at the university.

Three years ago, neuroscientists complained that large German research organizations were too passive in their response to animal rights activists (see Nature 396, 505; 1998).

But Kuno Kirschfeld, who deals with animal welfare at the Max Planck Society, one of Germany's largest research organizations, points out that the society cannot intervene unless there is illegal action or incitement to use violence.

The society has set up an office to deal with questions from the public about biological medicine, including animal experimentation. Its head is Jan Erik Bohling, a former spokesman for the Society for Health and Research. Bohling says he favours openness with the public and dialogue with groups such as BVTVG. 